Herz 2020 $45: 505$

https://doi.org/10.1007/s00059-020-04963-7

Published online: 1 July 2020

(c) Springer Medizin Verlag $\mathrm{GmbH}$, ein Teil von Springer Nature 2020

E. Nagel $\cdot$ M. L. Carerj ${ }^{1,2} \cdot$ C. T. Arendt ${ }^{1,3} \cdot$ V. O. Puntmann'

'Institute of Experimental and Translational Cardiac Imaging, DZHK Centre for Cardiovascular Imaging, University Hospital Frankfurt, Frankfurt am Main, Germany

${ }^{2}$ Section of Radiological Sciences, Department of Biomedical Sciences and Morphological and Functional; Imaging, Policlinico G. Martino, University Hospital Messina, Messina, Italy

${ }^{3}$ Department of Diagnostic and Interventional Radiology, University Hospital Frankfurt, Frankfurt am Main, Germany

\title{
Erratum to: After ISCHEMIA: Is cardiac MRI a reliable gatekeeper for invasive angiography and myocardial revascularization?
}

\section{Erratum to:}

Herz 2020

https://doi.org/10.1007/s00059-020-

04936-w

In the above mentioned article, the family name of the second author was not given correctly: it is Carerj instead of Careri.

The authors apologize for this mistake.

The original article has been corrected.

\section{Corresponding address}

Univ. Prof. Dr. med. E. Nagel, MD, PhD, FESC, FACC, FRCR

Institute of Experimental and Translational Cardiac Imaging, DZHK Centre for

Cardiovascular Imaging, University Hospital Frankfurt

Theodor-Stern-Kai 7, 60590 Frankfurt am Main,

Germany

eike.nagel@cardiac-imaging.org
The online version of the original article can be found under https://doi.org/10.1007/s00059020-04936-w. 